\title{
The impact of malocclusion on the oral health related quality of life of 11-14-year-old children
}

\author{
Jagan K. Baskaradoss ${ }^{*}$, Amrita Geevarghese ${ }^{2}$, Waad Alsaadi ${ }^{3}$, Huda Alemam ${ }^{4}$, Amjad Alghaihab5,6, \\ Amal Saad Almutairi ${ }^{7}$ and Abeer Almthen ${ }^{8}$
}

\begin{abstract}
Background: The relationship between malocclusion and the oral health related quality of life (OHRQoL) of children needs to be explored further as existing literature presents conflicting evidence. This study aims to determine the association between malocclusion and OHRQoL of 11-14-year-old children.

Methods: This cross-sectional study was conducted among 250 caregiver/child dyads seeking orthodontic consultation at a tertiary care hospital. The OHRQoL was assessed using child perception questionnaire for 11-14-year-old children ( $\left.C P Q_{11-14}\right)$ and the severity of malocclusion was assessed using the Dental Aesthetic Index (DAl). $C P Q_{11-14}$ scores ranged from 0 to 64, with lower scores representing better quality of life. Analysis of variance (ANOVA) was used to assess differences between domain and total $\mathrm{CPQ}_{11-14}$ scores.

Results: The mean $\mathrm{CPQ}_{11-14}$ score was $19.89 \pm 9.8$. Mean scores for the oral symptoms, functional limitations, emotional well-being, and social well-being domains were $5.26 \pm 3.22,3.67 \pm 3.58,3.98 \pm 3.89$ and $2.08 \pm 2.98$, respectively. Normal or slight malocclusion was seen in $37.6 \%$, definite malocclusion was seen in $22.4 \%$, severe malocclusion in $15.2 \%$ and handicapping malocclusion in $24.8 \%$ of the subjects. In comparisons by pairs, it was found that children with handicapping malocclusion had significantly $(p<0.05)$ higher scores for the social well-being domain as compared with children having normal/minor malocclusion, indicating a poorer quality of life.
\end{abstract}

Conclusion: Handicapping malocclusion had a significant negative impact on the social well-being domain of OHRQoL among 11-14-year-old children in this population.

\section{Background}

Malocclusion is a developmental condition where there is a deflection from the normal relation or alignment of the teeth to other teeth in the same arch and/or to the teeth in the opposing arch [1]. Malocclusion is one of the most common oral conditions, with a prevalence ranging from 20 to $100 \%$ [2-5]. A previous study from Saudi Arabia

\footnotetext{
*Correspondence: drjaganb@gmail.com

${ }^{1}$ Faculty of Dentistry, Division of Dental Public Health, Department

of Developmental and Preventive Sciences, Kuwait University,

Safat-13110, P.O. Box: 24923, Kuwait City, Kuwait

Full list of author information is available at the end of the article
}

reported a malocclusion prevalence of about 68\% [6]. Due to the high prevalence of malocclusion, the World Health Organization considers malocclusion to be a significant public health problem [7].

The oral health related quality of life (OHRQoL) is defined as a composition of self-report, specifically pertaining to oral health that captures the functional, social and psychological impacts of oral disease [8]. Malocclusion affects the function, appearance, social life and self-esteem of individuals, which constitute the different constructs of OHRQoL [9]. Since malocclusion can be perceived differently by different individuals, it is 
essential to understand the impact of malocclusion from the patients' perspective. The use of subjective measures along with the professionally determined treatment need has been shown to be beneficial in orthodontic treatment planning [10].

Several instruments have been used to assess the OHRQoL of children, Oral Health Impact Profile-14 (OHIP-14) [11], Child Oral Health Impact Profile (COHIP) [12], Early Childhood Oral Health Impact Scale (ECOHIS) [13], Child Perception Questionnaire (CPQ) [14], to mention a few. Though there are similarities in the constructs that are being assessed by these instruments, there are also differences. Some instruments tend to focus on the severity, whereas, others tend to focus on the frequency of oral impacts on the OHRQoL. Child Perceptions Questionnaire $\left(\mathrm{CPQ}_{11-14}\right)$ has been widely used to assess the quality of life of children in the age group of 11-14 years [15]. The long version $[6,16]$ and the short version [17] of $\mathrm{CPQ}_{11-14}$ has been cross-culturally validated in the Middle-Eastern population.

The Dental Aesthetic Index (DAI) is one of several indices used to measure malocclusion [18]. DAI has been widely used in orthodontic research due to its simplicity, reproducibility and validity. DAI has been adopted by the World Health Organization as a cross-cultural index to assess malocclusion in epidemiological studies [19] and it has been used in different populations without modifications $[20,21]$.

The relationship between malocclusion and the OHRQoL of children needs to be explored further as existing literature presents conflicting evidence, where some reports suggest a significant association [6, 22], while some others do not find an association [23-25]. Therefore, this study aims to determine the association between malocclusion and OHRQoL of 11-14-year-old children.

\section{Methods}

\section{Ethical approval}

This study received ethical approval from the Institutional Review Board (IRB) of King Abdullah International Medical Research Center (Study Number: SP17/353/R), and is reported according to the Strengthening the Reporting of observational Studies in Epidemiology (STROBE) guidelines for observational studies [26]. Written informed consent was obtained from those parents who agreed to participate in this study.

\section{Study design and study subjects}

This was a cross-sectional study based on a convenient sample from the orthodontic department at King Abdulaziz Medical City, Riyadh, Saudi Arabia, between July to December, 2017. Based on a previous study from a similar population [6], the expected effect size was assumed to be 0.15 , with a standard deviation of 0.45 , it was estimated that 250 participants would be required to obtain a power of $80 \%$ with a $95 \%$ confidence interval $(95 \% \mathrm{CI})$. All children who were undergoing or had undergone orthodontic treatment in the past were excluded from the study.

\section{Measures of OHRQoL and clinical oral examination}

Sociodemographic information was collected using a structured questionnaire from the parents who consented to participate in this study. The children completed the $\mathrm{CPQ}_{11-14}$ in the dental clinic waiting room just prior to the dental examination. $\mathrm{CPQ}_{11-14}$ consists of 4 close-ended questions for each of the four domains (oral symptoms, functional limitations, emotional well-being and social well-being). Each question was scored as: 0-never, 1-onceltwice, 2-sometimes, 3-often and 4-every daylalmost every day. The four domain scores were seperately added to give the total $\mathrm{CPQ}_{11-14}$ score, which ranged from 0 to 64 . Lower scores represent better quality of life.

Malocclusion was assessed using Dental Aesthetic Index (DAI) (the number of variables =10) [27]. The DAI measures 10 prominent traits of malocclusion, weighted on the basis of their relative importance, to produce a single score [1]. The 10 traits are: missing teeth, crowding, spacing, diastema, maxillary and mandibular anterior irregularity, overjet, reverse overjet, open bite and molar relationship. A DAI score of $\leq 25$ indicates normal or minor malocclusion (no treatment needed); a score of 26-30 indicates moderate or definite malocclusion (treatment is elective); a score of 31-35 denotes severe malocclusion (treatment considered as highly desirable); and a score of $\geq 36$ represents very severe (handicapping) malocclusion (mandatory treatment indicated) [27].

Five examiners underwent training and calibration for recording DAI at King Abdulaziz Medical City, Riyadh, Saudi Arabia. Kappa scores for inter- and intra-examiner reliability were $>0.80$.

\section{Statistical analysis}

Analysis of variance (ANOVA) or Student's t-test was used to assess the differences between $\mathrm{CPQ}_{11-14}$ scores and socio-demographic variables. Multivariate analysis of variance (MANOVA) was used to assess the relationship between DAI and $\mathrm{CPQ}_{11-14}$ scores, controlling for the socio-demographic variables. Post hoc comparisons between pairs of malocclusion groups were conducted using Bonferroni test. A $p$ value of $<0.05$ was chosen as the cut-off for statistical significance. Data analysis was performed with the Statistical Package for Social Sciences (SPSS Inc., Chicago, IL, USA). 


\section{Result}

A total of 250 child-parent dyads participated in this study. The distribution of socio-demographic variables by $\mathrm{CPQ}_{11-14}$ mean scores is shown in Table 1 . The domain and total scores of $\mathrm{CPQ}_{11-14}$ is shown in Table 2. The mean $\mathrm{CPQ}_{11-14}$ score was $19.89 \pm 9.8$. Table 3 presents severity of malocclusion across the different domain-specific scores of $\mathrm{CPQ}_{11-14}$. Mean scores for the oral symptoms, functional limitations, emotional well-being, and social well-being domains were $5.26 \pm 3.22,3.67 \pm 3.58$, $3.98 \pm 3.89$ and $2.08 \pm 2.98$, respectively. Domain-specific scores showed that the highest mean score was observed for the oral symptoms domain and the lowest score was observed for the social well-being domain. Normal or slight malocclusion was seen in $37.6 \%$, definite malocclusion was seen in $22.4 \%$, severe malocclusion in $15.2 \%$ and handicapping malocclusion in $24.8 \%$ of the subjects. Children with handicapping malocclusion had significantly higher scores (indicating a poorer quality of life) for the social well-being domain as compared with children who had normal/minor malocclusion. There was no statistically significant difference in domain or total $\mathrm{CPQ}_{11-14}$ scores by any of the sociodemographic variables.

\section{Discussion}

Subjective perception towards oral health is an important measure as it directly influences the oral health behaviors. In this study, handicapping malocclusion was found to negatively impact the social well-being domain

Table 1 Total Scores on the Child Perception Questionnaire $\left(\mathrm{CPQ}_{11-14}\right)$ for the socio-demographic variables

\begin{tabular}{|c|c|c|c|c|}
\hline Variables & & $\mathrm{N}(\%)$ & $\begin{array}{l}\mathrm{CPQ}_{11-14} \\
\text { Mean (SD) }\end{array}$ & $p$ value $^{\mathrm{b}}$ \\
\hline \multirow[t]{4}{*}{ Age } & 11 years & $106(42.4)$ & $20.14(9.90)$ & 0.20 \\
\hline & 12 years & $55(22.0)$ & $18.65(9.01)$ & \\
\hline & 13 years & $49(19.6)$ & $22.04(10.75)$ & \\
\hline & 14 years & $40(16.0)$ & $18.02(9.26)$ & \\
\hline \multirow[t]{2}{*}{ Gender } & Male & $64(25.6)$ & $19.45(10.88)$ & 0.68 \\
\hline & Female & $186(74.4)$ & $19.97(9.44)$ & \\
\hline \multirow[t]{4}{*}{ Mother's educational level ${ }^{\mathrm{a}}$} & Less than high school & $84(33.6)$ & $20.68(10.16)$ & 0.49 \\
\hline & High school or diploma & $73(29.2)$ & $19.57(8.43)$ & \\
\hline & Bachelor & $77(30.8)$ & $19.86(9.39)$ & \\
\hline & Master and above & $11(3.2)$ & $18.75(21.78)$ & \\
\hline \multirow[t]{4}{*}{ Father's educational level ${ }^{a}$} & Less than high school & $47(18.8)$ & $20.91(11.09)$ & 0.26 \\
\hline & High school or diploma & $97(38.8)$ & $20.11(9.10)$ & \\
\hline & Bachelor & $83(33.2)$ & $18.79(8.85)$ & \\
\hline & Master and above & $17(5.2)$ & $24.00(17.45)$ & \\
\hline \multirow[t]{4}{*}{ Family monthly income ${ }^{a}$} & Less than 5000 SAR & $42(16.8)$ & $22.09(12.36)$ & 0.40 \\
\hline & 5000-15,000 SAR & $88(35.2)$ & $20.10(9.02)$ & \\
\hline & $15,000-20,000$ SAR & $72(28.8)$ & $18.94(8.12)$ & \\
\hline & More than 20,000 SAR & $38(15.2)$ & $19.44(11.89)$ & \\
\hline
\end{tabular}

${ }^{a}$ Presence of missing values

${ }^{\mathrm{b}}$ ANOVA or Student's t-test

SAR Saudi Arabian Riyals

Table 2 Domain and Total Scores on the Child Perception Questionnaire $\left(\mathrm{CPQ}_{11-14}\right)$ for 11- to 14-year-old children in the sample

\begin{tabular}{lllll}
\hline Items & No. of Items & Possible Range & Observed Range & Mean (SD) \\
\hline Oral symptoms & 4 & $0-16$ & $0-16$ & $5.26(3.22)$ \\
Functional limitation & 4 & $0-16$ & $0-16$ & $3.67(3.58)$ \\
Emotional well-being & 4 & $0-16$ & $0-16$ & $3.98(3.89)$ \\
Social well-being & 4 & $0-16$ & $0-16$ & $2.08(2.98)$ \\
Total $C \mathrm{PQ}_{11-14}$ score & 16 & $0-64$ & $2-62$ & $19.89(9.80)$ \\
\hline
\end{tabular}


Table 3 Domain and Total Scores on the Child Perception Questionnaire for 11- to 14-year-old Children $\left(C^{2} Q_{11-14}\right)$ by Dental Aesthetic Index (DAI) Malocclusion Severity

\begin{tabular}{lllllll}
\hline Severity of Malocclusion & $\mathbf{N}(\%)$ & \multicolumn{2}{l}{ Oral health related quality of life (OHRQoL) } \\
\cline { 3 - 7 } & & $\begin{array}{l}\text { Oral symptoms } \\
\text { Mean(SD) }\end{array}$ & $\begin{array}{l}\text { Functional limitation } \\
\text { Mean(SD) }\end{array}$ & $\begin{array}{l}\text { Emotional } \\
\text { well-being } \\
\text { Mean(SD) }\end{array}$ & $\begin{array}{l}\text { Social well-being } \\
\text { Mean(SD) }\end{array}$ & $\begin{array}{l}\text { Total CPQ } \\
\text { Mean(SD) }\end{array}$ \\
\hline Normal/Minor & & & $3.55(3.60)$ & $3.92(3.97)$ & $1.51(2.33)^{\mathrm{a}}$ & $19.62(9.83)$ \\
Definite & $94(37.6)$ & $5.283 .17)$ & $3.53(3.25)$ & $3.43(3.54)$ & $1.75(2.54)$ & $18.59(8.14)$ \\
Severe & $56(22.4)$ & $4.80(2.85)$ & $3.57(4.38)$ & $3.68(4.26)$ & $2.65(4.08)$ & $20.42(13.05)$ \\
Very severe & $38(15.2)$ & $5.71(3.86)$ & $3.87(3.38)$ & $4.80(3.76)$ & $2.88(3.20)^{\mathrm{a}}$ & $21.16(8.83)$ \\
Total Mean Score & $62(24.8)$ & $5.40(3.22)$ & $3.67(3.58)$ & $3.98(3.89)$ & $2.08(2.98)$ & $19.89(9.80)$ \\
\hline
\end{tabular}

a Superscripts indicate which pairs of malocclusion severity groups were statistically different $(p<0.05)$ using Multivariate analysis of variance

of $\mathrm{CPQ}_{11-14}$. Social well-being domain reflects the child's quality of life with regard to the appearance of their dentition, self-esteem related to oral health, and their interaction with peers [28]. Similar associations between DAI scores and social well-being domain were reported in other studies as well $[6,22]$. DAI is an orthodontic treatment index that is designed to assess the orthodontic needs based on the socially defined esthetic standards [29]. Therefore, it is recognized that DAI is sensitive to the social and emotional domains of quality of life measures.

In this study, children with definite malocclusion had the lowest $\mathrm{CPQ}_{11-14}$ scores and children with handicapping malocclusion had the highest $\mathrm{CPQ}_{11-14}$ scores. A clear gradient for the total $\mathrm{CPQ}_{11-14}$ scores was not observed across the four categories and the difference between groups were not statistically significant. Dawoodbhoy et al. [6] and Locker et al. [30] also reported a lack of a clear gradient across different levels of malocclusion. However, Kassis et al.[31] observed a clear ascending gradient for $\mathrm{CPQ}_{11-14}$ score across ascending categories of orthodontic treatment need. The difference may be due to differences in the sample characteristics and the distribution of subjects and sample sizes across the four treatment need categories.

As with any quality of life study, respondents' socio economic factors are considered to be important confounders. Foster Page et al. [32] found that the mean emotional well-being domain score was higher for girls than for boys. However, in this study, no significant difference in the total $\mathrm{CPQ}_{11-14}$ scores were observed between the genders. Other studies have also reported that females and males are equally affected on all the four domains of $\mathrm{CPQ}_{11-14}[33,34]$.

The OHRQoL measures have the potential to provide an unique perspective of how oral conditions affect an individual's everyday life, which is crucial for the dentist to understand the patients' treatment needs [24].
Our findings suggest that clinicians should consider subjective measures like the quality of life along with their clinical assessment during treatment planning. These subjective measures can complement the traditional or the professionally determined orthodontic treatment needs.

The results of this study should be interpreted with caution due to limitations relating to the lack of representativeness of the study sample. This was a hospitalbased study which recruited a convenient sample from patients reporting to the orthodontic department at the dental centre. This limits the ability to extrapolate the study findings to the general population. In addition, $\mathrm{CPQ}_{11-14}$ is not a malocclusion specific OHRQoL measure, and as such, it captures the effects on the quality of life attributed by the general oral health conditions.

\section{Conclusions}

Handicapping malocclusion had a significant negative impact on the social well-being domain of OHRQoL among 11-14-year-old children in this population. The findings of this study provides additional evidence that handicapping malocclusion negatively impacts the oral health related quality of life.

\section{Abbreviations}

CPQ: Child perception questionnaire; DAI: Dental Aesthetic Index; OHRQoL: Oral health related quality of life.

\section{Acknowledgements}

The authors thank all the parents and children who participated in this study.

\section{Authors' contributions}

AG and JKB designed the study and have taken an active role in data collection, analysis and drafting and revising the manuscript. WA, HA,AAG, ASA and AAM have taken an active role in data collection, analysis and drafting the manuscript. All the authors have read and approved the final manuscript. 


\section{Funding}

This study did not receive financial support from any sources. The authors would like to the thank Kuwait University Research Sector for funding the article-processing charges of this publication.

\section{Availability of data and materials}

Data used in this study is available from the corresponding author upon reasonable request.

\section{Declarations}

\section{Ethics approval and consent to participate}

Ethical approval for this study was obtained from the Institutional Review Board (IRB) of King Abdullah International Medical Research Centre, Riyadh, Saudi Arabia. Informed consent was obtained from the caregivers, and the study is reported in accordance with the guidelines of Strengthening the Reporting of Observational Studies in Epidemiology (STROBE) for observational clinical studies. Protocols documented in the 2013 Helsinki Declaration of Experiments on Humans were adopted for this study.

\section{Consent for publication}

Consent was obtained from the parents of every individual whose data are included in this manuscript.

\section{Competing interests}

The authors declare that they have no competing interests.

\section{Author details}

${ }^{1}$ Faculty of Dentistry, Division of Dental Public Health, Department of Developmental and Preventive Sciences, Kuwait University, Safat-13110, P.O. Box: 24923, Kuwait City, Kuwait. ${ }^{2}$ Division of Oral Epidemiology and Dental Public Health, Department of Preventive and Restorative Dental Sciences, School of Dentistry, University of California San Francisco, San Francisco, CA, USA. ${ }^{3}$ Department of Pediatric Dentistry and Orthodontics, College of Dentistry, King Saud University, Riyadh, Saudi Arabia. ${ }^{4}$ Saudi board of pediatric dentistry, Riyadh, Saudi Arabia. ${ }^{5}$ Department of Maxillofacial Surgery and Diagnostic Sciences, College of Dentistry, King Saud bin Abdulaziz University for Health Sciences, Riyadh, Saudi Arabia. ${ }^{6}$ King Abdullah International Medical Research Center, Ministry of National Guard Health Affairs, Riyadh, Saudi Arabia. ${ }^{7}$ Ministry of Health, Kuwait city, Kuwait. ${ }^{8}$ Advanced Education in General Dentistry, Ministry of National Guard, Riyadh, Saudi Arabia.

Received: 5 August 2021 Accepted: 15 January 2022

Published online: 14 February 2022

\section{References}

1. Baskaradoss JK, Bhagavatula P. Burt and Eklund's Dentistry, Dental Practice, and the Community. In: Mascarenhas AK, Okunseri C, Dye B, editors. Measurement and Distribution of Malocclusion, Trauma, and Congenital Anomalies. 7th ed. Philadelphia: WB Saunders Company; 2020. p. 208-17.

2. Proffit WR, Fields HW Jr, Moray $\sqcup$. Prevalence of malocclusion and orthodontic treatment need in the United States: estimates from the NHANES III survey. Int J Adult Orthodon Orthognath Surg. 1998;13(2):97-106.

3. Thilander B, Pena L, Infante C, Parada SS, de Mayorga C. Prevalence of malocclusion and orthodontic treatment need in children and adolescents in Bogota, Colombia. An epidemiological study related to different stages of dental development. Eur J Orthod. 2001;23(2):153-67.

4. Borzabadi-Farahani A, Borzabadi-Farahani A, Eslamipour F. Malocclusion and occlusal traits in an urban Iranian population. An epidemiological study of 11- to 14-year-old children. Eur J Orthod. 2009;31(5):477-84.

5. Grippaudo C, Paolantonio EG, Deli R, La Torre G. Orthodontic treatment need in the Italian child population. Eur J Paediatr Dent. 2008;9(2):71-5.

6. Dawoodbhoy I, Delgado-Angulo EK, Bernabe E. Impact of malocclusion on the quality of life of Saudi children. Angle Orthod. 2013;83(6):1043-8.

7. World Health Organization (WHO). Health through oral health: guidelines for planning and monitoring for oral health care. World Health Organization (WHO) and Fédération Dentarie Internationale. London: Quintessence; 1989.
8. Gift HC, Atchison KA, Dayton CM. Conceptualizing oral health and oral health-related quality of life. Soc Sci Med. 1997;44(5):601-8.

9. Aldrigui JM, Abanto J, Carvalho TS, Mendes FM, Wanderley MT, Bonecker M, Raggio DP. Impact of traumatic dental injuries and malocclusions on quality of life of young children. Health Qual Life Outcomes. 2011;9:78.

10. Barbosa TS, Gaviao MB. Oral health-related quality of life in children: part II. Effects of clinical oral health status. a systematic review. Int J Dent Hyg 2008;6(2):100-7.

11. Slade GD. Derivation and validation of a short-form oral health impact profile. Community Dent Oral Epidemiol. 1997;25(4):284-90.

12. Broder HL, MCGrath C, Cisneros GJ. Questionnaire development: face validity and item impact testing of the Child Oral Health Impact Profile. Community Dent Oral Epidemiol. 2007;35(Suppl 1):8-19.

13. Pahel BT, Rozier RG, Slade GD. Parental perceptions of children's oral health: the Early Childhood Oral Health Impact Scale (ECOHIS). Health Qual Life Outcomes. 2007:5:6

14. Jokovic A, Locker D, Stephens M, Kenny D, Tompson B, Guyatt G. Validity and reliability of a questionnaire for measuring child oral-health-related quality of life. J Dent Res. 2002;81(7):459-63.

15. Feu D, de Oliveira BH, de Oliveira Almeida MA, Kiyak HA, Miguel JA. Oral health-related quality of life and orthodontic treatment seeking. Am J Orthod Dentofacial Orthop. 2010;138(2):152-9.

16. Brown A, Al-Khayal Z. Validity and reliability of the Arabic translation of the child oral-health-related quality of life questionnaire (CPQ11-14) in Saudi Arabia. Int J Paediatr Dent. 2006;16(6):405-11.

17. Bhayat A, Ali MA. Validity and reliability of the Arabic short version of the child oral health-related quality of life questionnaire (CPQ 11-14) in Medina. Saudi Arabia East Mediterr Health J. 2014;20(8):477-82.

18. Cons NC, Jenny J, Kohout FJ, Songpaisan Y, Jotikastira D. Utility of the dental aesthetic index in industrialized and developing countries. J Public Health Dent. 1989:49(3):163-6.

19. World Health Organization. Oral health surveys: basic Methods, 5th edition. Geneva: World Health Organization; 2013.

20. Baskaradoss JK, Geevarghese A, Roger C, Thaliath A. Prevalence of malocclusion and its relationship with caries among school children aged 11-15 years in southern India. Korean J Orthod. 2013;43(1):35-41.

21. Cons NC, Jenny J, Kohout FJ, Jakobsen J, Shi Y, Ying WH, Pakalns G. Comparing ethnic group-specific DAl equations with the standard DAI. Int Dent J. 1994;44(2):153-8.

22. Agou S, Locker D, Streiner DL, Tompson B. Impact of self-esteem on the oral-health-related quality of life of children with malocclusion. Am J Orthod Dentofacial Orthop. 2008;134(4):484-9.

23. Barbosa TS, Tureli MC, Gaviao MB. Validity and reliability of the Child Perceptions Questionnaires applied in Brazilian children. BMC Oral Health. 2009;9:13.

24. Locker D, Allen F. What do measures of "oral health-related quality of life" measure? Community Dent Oral Epidemiol. 2007;35(6):401-11.

25. Kolawole KA, Otuyemi OD, Oluwadaisi AM. Assessment of oral healthrelated quality of life in Nigerian children using the Child Perceptions Questionnaire (CPQ 11-14). Eur J Paediatr Dent. 2011;12(1):55-9.

26. Von Elm E, Altman DG, Egger M, Pocock SJ, Gøtzsche PC, Vandenbroucke $J$ P, Initiative S. The Strengthening the Reporting of Observational Studies in Epidemiology (STROBE) statement: guidelines for reporting observational studies. PLoS medicine. 2007;4(10):e296.

27. Jenny J, Cons NC, Kohout FJ, Jakobsen J. Predicting handicapping malocclusion using the Dental Aesthetic Index (DAl). Int Dent J. 1993;43(2):128-32.

28. Kragt L, Dhamo B, Wolvius EB, Ongkosuwito EM. The impact of malocclusions on oral health-related quality of life in children-a systematic review and meta-analysis. Clin Oral Investig. 2016;20(8):1881-94.

29. Jenny J, Cons NC. Establishing malocclusion severity levels on the Dental Aesthetic Index (DAl) scale. Aust Dent J. 1996;41(1):43-6.

30. Locker D, Jokovic A, Tompson B, Prakash P. Is the Child Perceptions Questionnaire for 11-14 year olds sensitive to clinical and self-perceived variations in orthodontic status? Community Dent Oral Epidemiol. 2007;35(3):179-85.

31. Kassis A, El Osta N, Tubert-Jeannin S, Hennequin M, El Osta L, Ghoubril J. Cross-cultural adaptation and validation of the child perceptions questionnaire (CPQ11-14) among children in Lebanon. BMC Oral Health. 2018;18(1):18

32. Foster Page LA, Thomson WM, Jokovic A, Locker D. Validation of the Child Perceptions Questionnaire (CPQ 11-14). J Dent Res. 2005;84(7):649-52. 
33. de Paula Junior DF, Santos NC, da Silva ET, Nunes MF, Leles CR. Psychosocial impact of dental esthetics on quality of life in adolescents. Angle Orthod. 2009;79(6):1188-93.

34. Tessarollo FR, Feldens CA, Closs LQ. The impact of malocclusion on adolescents' dissatisfaction with dental appearance and oral functions. Angle Orthod. 2012;82(3):403-9.

\section{Publisher's Note}

Springer Nature remains neutral with regard to jurisdictional claims in published maps and institutional affiliations.

- fast, convenient online submission

- thorough peer review by experienced researchers in your field

- rapid publication on acceptance

- support for research data, including large and complex data types

- gold Open Access which fosters wider collaboration and increased citations

- maximum visibility for your research: over 100M website views per year

At $\mathrm{BMC}$, research is always in progress.

Learn more biomedcentral.com/submissions 